\title{
Atypical Familial Dysbetalipoproteinemia Associated with Apolipoprotein Phenotype E3/3
}

\author{
Richard J. Havel, Leila Kotite, John P. Kane, Peggy Tun, and \\ ThOMAS BERSOT, Cardiovascular Research Institute, Gladstone Foundation \\ Laboratories for Cardiovascular Disease and Department of Medicine, \\ University of California, San Francisco, California 94143
}

A B S T R A C T Familial dysbetalipoproteinemia has been reported to be associated uniquely with an apolipoprotein E phenotype (E2/2) that occurs in $\sim 1 \%$ of all persons. We have observed the typical clinical and biochemical characteristics of this disorder in five members of a family, in all of whom the apolipoprotein E phenotype, as determined by isoelectric focusing electrophoresis, is E3/3. The disorder is present in three generations of the family: the proband, her mother, and three of the proband's five children. The proband's husband, father of all five children, also has apolipoprotein E phenotype E3/3, as do his two unaffected children. As in normal persons with phenotype E3/3, the apolipoprotein $E$ of affected members appears to have a single residue of cysteine. When incorporated with egg lecithin into discoidal complexes, the apolipoprotein E from affected members was taken up normally into perfused livers of estradiol-treated rats, in which a high level of LDL receptors is expressed. When isoelectric focusing electrophoresis was carried out over a narrow range of $\mathrm{pH}(5-7)$, each of the apolipoprotein $\mathrm{E}$ isoforms of affected members was observed as a doublet, even after reduction of dimers of the protein with 2-mercaptoethanol and treatment with neuraminidase to minimize the content of sialylated forms of the protein. Doublets were also observed in the apolipoprotein E-2 of patients with classical dysbetalipoproteinemia, but only in the affected members of the family with atypical dysbetalipoproteinemia were the components of the doublets equally prominent. As in classical dysbetalipoproteinemia, both apolipoprotein B-100 and B-48 were present in the very low density lipoprotein fraction of plasma obtained in the postabsorptive state, indicating that remnantlike lipoproteins of both hepatic and intestinal

Received for publication 27 September 1982 and in revised form 24 January 1983. origin accumulate. This observation, together with available evidence on the structural and functional heterogeneity of human apolipoprotein $E$, lead us to suggest that the disorder in this family is caused by one or two structurally abnormal forms of apolipoprotein $\mathrm{E}$ that contain a single residue of cysteine.

\section{INTRODUCTION}

Familial dysbetalipoproteinemia is a distinctive disorder of the plasma lipoproteins associated with the accumulation of triglyceride-rich lipoproteins that contain increased amounts of cholesteryl esters and apolipoprotein (apo) ${ }^{1}$ E (1). Apo E exhibits genetic polymorphism dictated by several alleles at a common locus (3). By isoelectric focusing gel electrophoresis, three forms of the protein can be distinguished that differ in pI by a single charge unit, owing to cysteinearginine interchanges at one or two sites (4). The form of the protein thus designated as E-4 contains no cysteine, that designated at E-3 contains one cysteine, and that designated as E-2 contains two cysteines. Apo E is a single polypeptide chain containing 299 amino acids (5). E-3 has been found to contain cysteine at position 112, and E-2 to contain an additional residue of cysteine at either position 158 or position 145 (5, 6). Persons with familial dysbetalipoproteinemia described to date have, with the exception of one kindred in whom apo $E$ is absent (7), been found to be homozygous for alleles specifying E-2 (phenotype E2/2). The form of E-2 containing cysteine at positions 112 and 158 is poorly recognized by the low density lipoprotein (LDL) receptor in cultured human fibroblasts and by lipoprotein receptors in membrane preparations of bovine adrenal gland and rat liver, but the

\footnotetext{
${ }^{1}$ Abbreviations used in this paper: apo, apolipoprotein; $\mathrm{E} 3 / 3, \mathrm{E2} / 2$ denote phenotypes of apo E, designated according to a recently proposed system of nomenclature (2).
} 
form of E-2 containing cysteine at positions 112 and 145 is recognized to a much greater extent by these receptors, albeit not quite normally $(6,8)$. However, these differences in biological behavior are not associated with obvious differences in the expression of dysbetalipoproteinemia.

We report here our studies of a kindred in whom the clinical features of dysbetalipoproteinemia are associated with the accumulation of triglyceride-rich lipoproteins having all of the properties that characterize this disorder with the exception that the apo $E$ phenotype in unaffected and affected members alike is E3/3. The disorder appears in three generations of this family, thus having characteristics of a dominant trait. The E-3 in affected members is functionally competent with respect to its interaction with the LDL receptor in rat liver and the triglyceride-rich lipoproteins are recognized by the $\beta$-very low density lipoprotein (VLDL) receptor on mouse macrophages (T. P. Bersot, T. L. Innerarity, R. W. Mahley, and R. J. Havel, submitted for publication).

\section{METHODS}

Lipid and lipoprotein analysis. Lipoproteins were separated by preparative ultracentrifugation of serum from blood obtained from antecubital veins of members of the A. kindred who had fasted 9-15 h. For measurement of the concentration of total cholesterol and triglycerides (9) and apo $\mathrm{E}(10)$ in three major lipoprotein fractions, samples were subjected to ultracentrifugation at densities of 1.006 and $1.063 \mathrm{~g} / \mathrm{ml}(11)$. For measurement of the composition (12) of lipoprotein classes, lipoproteins were separated by sequential ultracentrifugation (13) and purified and concentrated by recentrifugation at the respective upper density limits. Apo B in VLDL was determined as protein insoluble in tetramethylurea (14) and content of other apoproteins of VLDL, delipidated with ethanol/ether, 3:1 (15), was determined by quantitative densitometric analysis of polyacrylamide gel electrophoretograms stained with Amidoschwarz (14). The presence of different forms of apo B in VLDL was determined by sodium dodecyl sulfate (SDS) electrophoresis in $3 \%$ polyacrylamide gels (16).

Analysis of apo $E$ and its isoforms. Distribution of isoforms of apo $\mathrm{E}$ was determined by analytical isoelectric focusing polyacrylamide gel electrophoresis (17), with a $\mathbf{p H}$ gradient of 3.5-7.0 or 5.0-7.0. Samples of apo VLDL were analyzed routinely with and without reduction of disulfides with 2-mercaptoethanol (10). To determine the effect of desialylation upon the isoelectric focusing pattern, samples of apo VLDL were incubated with neuraminidase (from Clostridium perfringens, $0.6 \mathrm{U} / \mathrm{ml}$, Boehringer Mannheim Biochemicals, Indianapolis, IN) before electrophoresis. VLDL ( $\sim 2 \mathrm{mg}$ protein in $1 \mathrm{ml} 0.15 \mathrm{M} \mathrm{NaCl}$ and $0.02 \mathrm{M}$ sodium acetate, $\mathrm{pH} 5.2$, or apo $\mathrm{E}(50-100 \mu \mathrm{g}$ in $0.1 \%$ sodium decyl sulfate, $0.02 \mathrm{M}$ sodium acetate, $\mathrm{pH}$ 5.2) was incubated with $0.01 \mathrm{U}$ neuraminidase $/ \mathrm{mg}$ protein for $30 \mathrm{~min}$ at $37^{\circ} \mathrm{C}$. Twodimensional electrophoresis of apo VLDL was performed as described by Menzel et al. (18) with $5 \%$ polyacrylamide gel for the first dimension and $12 \%$ gel for the second dimension. Apo E was isolated from VLDL delipidated with tetramethylurea and diethyl ether by gel filtration chromatography
(19). Composition of apo $\mathrm{E}$ was determined by amino acid analysis (20). The number of cysteine residues was evaluated by isoelectric focusing electrophoresis of apo $\mathrm{E}$ in apo VLDL reacted with cysteamine $(21)$.

Other procedures and analyses. Apo $\mathrm{E}$ was iodinated with ${ }^{125}$ I and complexed with egg phosphatidylcholine (22). Uptake of the ${ }^{125} \mathrm{I}$-apo $\mathrm{E}$ was measured in single-pass perfusions of isolated rat livers (22). Total and salt-insensitive lipolytic activities were estimated in plasma obtained $10 \mathrm{~min}$ after intravenous injection of $1.0 \mathrm{mg}$ heparin $/ \mathrm{kg}$ body weight (23).

\section{RESULTS}

Clinical features of the A. kindred. The proband, Ad.A., and her family emigrated to California from El Salvador in 1960. She was found to have palmar xanthomas, hyperlipidemia, and hypertension in 1971. Clofibrate, $1.5 \mathrm{~g} / \mathrm{d}$, and antihypertensive medications were prescribed, with disappearance of the xanthomas and reduction of blood pressure. Concentrations of cholesterol and triglyceride remained at levels of $300-$ $400 \mathrm{mg} / \mathrm{dl}$. In 1978, she underwent a left renal thromboendarterectomy and repair of an abdominal aortic aneurysm. She was first seen in the Lipid Clinic at the University of California, San Francisco, in August, 1979. Plasma cholesterol and triglycerides were found to be grossly elevated and findings upon lipoprotein analysis were typical of dysbetalipoproteinemia (Table I). She had no symptoms of ischemic vascular disease and no xanthomas were evident. She was placed on nicotinic acid, $0.7 \mathrm{~g}$ three times daily, in September, 1979 , with reduction of serum cholesterol to $180-240$ $\mathrm{mg} / \mathrm{dl}$ and serum triglycerides to $135-200 \mathrm{mg} / \mathrm{dl}$. Medications for hypertension (hydrochlorothiazide, 50 $\mathrm{mg}$ twice daily, and propranolol, $120 \mathrm{mg}$ twice daily) have been continued.

The proband's mother, G.P., was found.to be hyperlipidemic in 1965, at which time she had yellowish, elevated lesions over her elbows and yellowish discoloration of the palmar creases. Clofibrate was prescribed (1.0-1.5 $\mathrm{g}$ daily), with disappearance of the presumed xanthomas. She was found to be hypertensive in May, 1980, and placed on hydrochlorothiazide. Lipoprotein analysis was typical for dysbetalipoproteinemia (Table I). Corneal arcus was evident but no xanthomas were evident. An abdominal aortic aneurysm was repaired in June, 1980 . She has little knowledge of her parents, except that her mother died in her sixties. She is an only child.

The proband's parents are second cousins, once removed. Three of her five children (Jo.A, R.A., and M.A.A.) were found to have typical dysbetalipoproteinemia and all were hyperlipidemic (Table I). R.A. had small, raised yellow lesions in the web of both hands between the first and second digits. Jo.A. had a diminished right posterior tibial pulse and absent left 
TABLE I

Concentration of Serum and Lipoprotein Lipids and Apo E in the A. Family (mg/dl)

\begin{tabular}{|c|c|c|c|c|c|c|c|c|c|c|c|c|c|c|c|}
\hline \multirow[b]{2}{*}{ Patient } & \multirow{2}{*}{$\begin{array}{l}\text { Kindred } \\
\text { position }\end{array}$} & \multirow[b]{2}{*}{ Sex } & \multirow[b]{2}{*}{ Age } & \multicolumn{3}{|c|}{ Serum } & \multicolumn{3}{|c|}{ VLDL } & \multicolumn{3}{|c|}{$\mathrm{IDL}+\mathrm{LDL}$} & \multicolumn{3}{|c|}{ HDL } \\
\hline & & & & TC & TG & Apo E & TC & TG & Apo E & TC & TG & Apo E & TC & TG & Apo E \\
\hline & & & $y r$ & & & & & & & & & & & & \\
\hline G.P. ${ }^{\circ}$ & I-1 & $\mathbf{F}$ & 66 & 179 & 110 & 9.9 & 45 & 72 & - & 90 & 26 & - & 36 & 14 & - \\
\hline Ad.A. & II-1 & $\mathbf{F}$ & 45 & 630 & 623 & 56.9 & 354 & 500 & - & 222 & 76 & - & 33 & 22 & - \\
\hline Jo.A. & III-2 & $\mathbf{M}$ & 20 & 380 & 212 & 29.5 & 95 & 140 & 12.5 & 232 & 35 & 8.7 & 41 & 19 & 2.9 \\
\hline M.A.A. & III-3 & $\mathbf{F}$ & 17 & 216 & 195 & 23.3 & 81 & 123 & 14.0 & 103 & 26 & 4.3 & 29 & 14 & 1.6 \\
\hline R.A. & III-4 & $\mathbf{F}$ & 16 & 330 & 188 & 25.0 & 90 & 127 & 10.5 & 207 & 46 & 63 & 32 & 16 & 6.5 \\
\hline M.G.A. & III-1 & $\mathbf{F}$ & 21 & 195 & 93 & 4.7 & 8 & 49 & - & 154 & 18 & - & 31 & 20 & - \\
\hline Ju.A. & III-5 & $\mathbf{M}$ & 12 & 230 & 53 & 6.5 & 6 & 21 & 0.48 & 192 & 22 & 2.1 & 42 & 10 & 3.5 \\
\hline Ar.A. & II-2 & $\mathbf{M}$ & 45 & 218 & 83 & 4.3 & 15 & 41 & 0.79 & 172 & 31 & 0.8 & 29 & 12 & 2.3 \\
\hline
\end{tabular}

- During treatment with clofibrate; no hypolipidemic drugs were being taken by others tested.

dorsalis pedal pulse. The composition of the lipoproteins of the other two children (M.G.A. and Ju.A.) was normal, but one (Ju.A.) had increased cholesterol levels in serum and intermediate density lipoprotein (IDL) plus LDL.

The proband's husband, Ar.A., father of all five children, was found to be hypertriglyceridemic $(489 \mathrm{mg} /$ dl) on one occasion, when he was drinking $\sim 2.5$ liters of beer daily, but was later normolipidemic after he had stopped drinking and had lost weight (Table I). He had no xanthomas or evidence of ischemic vascular disease. Ad.A. and Ar.A. come from the same small town in El Salvador, but careful questioning revealed no evidence that they are genetically related. The pedigree of the A. family is summarized in Fig. 1.

Lipid and lipoprotein analyses. All five of the affected members of the kindred had elevated serum triglyceride levels and all but one have had elevated serum cholesterol levels when hyperlipidemic drugs were not given (Table I). The levels of these lipids have responded well to clofibrate or nicotinic acid in the proband (Ad.A.) and her mother (G.P.). In affected members, VLDL of beta electrophoretic mobility were present (Table II) and the ratio of total cholesterol to

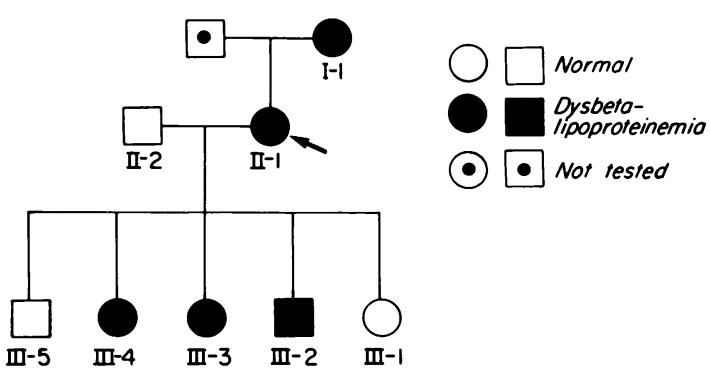

Figure 1 Pedigree of the A. kindred. triglycerides in VLDL varied between 0.63 and 0.75 (Table I). The ratio in the two unaffected children was 0.16 and 0.29 and $\beta$-VLDL were absent in them and the proband's husband (Ar.A). All affected members (except G.P., who was taking clofibrate) had grossly elevated levels of apo $E$ in serum and VLDL. Levels of cholesterol in IDL plus LDL varied, but in affected members tested, the levels of apo $E$ in this fraction were increased, consistent with the presence of remnantlike particles. The composition of the VLDL of the proband was typical of dysbetalipoproteinemia, with increased content of cholesteryl esters and reduced content of triglycerides (Table III). The composition of the IDL, LDL, and high density lipoprotein (HDL) was normal (24). Several members of the kindred had reduced HDL-cholesterol levels, including the unaffected husband of the proband and one of his two unaffected children. Apo E comprised an abnormally large fraction of the protein component of VLDL in dysbetalipoproteinemic members, but was well within normal limits (10) in those not affected (Table II).

Isoelectric focusing electrophoresis of apo VLDL. The variation of isoelectric behavior of apo $E$ appears to result both from polymorphism of the gene dictating the structure of apo $\mathrm{E}$ and from posttranslational modifications of the protein $(1,3)$. Reduction of disulfide dimers of apo E (apo E-apo E or apo E-apo A-II) simplifies the pattern in most persons $(1,10)$ and facilitates assignment of apo $\mathrm{E}$ phenotype. Apo $\mathrm{E}$ is a glycoprotein that appears to be variably sialylated (3), so that treatment of apo VLDL with neuraminidase further simplifies the pattern of apo $\mathrm{E}$ in isoelectric focusing gels (1).

The isoelectric focusing pattern of apo $\mathrm{E}$ in the proband was virtually indistinguishable from that of the E3/3 phenotype, when apo $\mathrm{E}$ was reduced with 2- 
TABLE II

Apoprotein Composition of VLDL

\begin{tabular}{|c|c|c|c|c|c|c|c|c|c|c|}
\hline \multirow[b]{2}{*}{ Patient } & \multirow{2}{*}{$\begin{array}{c}\text { Electrophoretic } \\
\text { mobility of } \\
\text { VLDL }\end{array}$} & \multirow[b]{2}{*}{ E-3:E-2• } & \multicolumn{8}{|c|}{ Component ( $\%$ mass) } \\
\hline & & & B & $\mathbf{E}$ & C-I & C-II & C-III-0 & C-III-I & C-III-2 & C-111-3 \\
\hline G.P. & $\beta+$ pre $-\beta$ & 2.79 & 49.5 & 18.9 & 2.7 & 5.5 & 2.2 & 10.8 & 7.9 & 2.8 \\
\hline Ad.A. & $\beta+$ pre $-\beta$ & 3.03 & 52.1 & 26.0 & 3.1 & 2.7 & 1.3 & 8.6 & 4.8 & 0.7 \\
\hline Jo.A. & $\beta$ & 3.27 & 59.9 & 19.6 & 2.3 & 3.1 & 1.4 & 7.6 & 4.5 & 1.6 \\
\hline M.A.A. & $\beta+$ pre $-\beta$ & 2.83 & 43.8 & 24.8 & 3.3 & 4.3 & 1.7 & 11.8 & 7.7 & 2.8 \\
\hline R.A. & $\beta+$ pre $-\beta$ & 3.04 & 54.4 & 23.8 & 2.8 & 3.4 & 1.2 & 6.2 & 4.8 & 2.1 \\
\hline M.G.A. & double pre- $\beta$ & 3.15 & 38.4 & 9.3 & 5.3 & 9.6 & 4.4 & 18.8 & 11.1 & 3.1 \\
\hline Ju.A. & double pre- $\beta$ & 1.83 & 49.0 & 7.9 & 3.9 & 7.0 & 3.6 & 13.7 & 10.8 & 4.2 \\
\hline Ar.A. & Single pre- $\beta$ & 1.96 & 47.1 & 5.8 & 4.1 & 9.5 & 3.7 & 12.8 & 13.7 & 3.4 \\
\hline
\end{tabular}

- As determined by isoelectric focusing gel electrophoresis, in the presence of 2-mercaptoethanol.

mercaptoethanol, with or without treatment of apo VLDL with neuraminidase (Fig. 2). The E-3/E-2 ratio in the proband and in the other four affected members of the kindred ranged from 2.79 to 3.27 (Table II), consistent with an E3/3 phenotype. This was confirmed by two-dimensional electrophoretic analysis, which showed the predominant unsialylated apo $\mathbf{E}$ component to be E-3 (Fig. 3). However, in one-dimensional gels run in the absence of 2 -mercaptoethanol, the isoforms with pI of E-3 and E-2 were each seen as a closely spaced doublet (Fig. 2). This pattern appeared to be identical in all five affected members of the kindred (Fig. 4). Isoforms with $\mathrm{pI}$ in the region of E-1 usually appeared as a doublet with and as a triplet without treatment of apo VLDL with 2-mercaptoethanol (compare upper and lower groups of gels in Fig. 3).

Mixing experiments showed that the more anionic member of the doublet of the apo E-3 bands of affected members of the A. kindred co-focused with the E-3 from unaffected individuals (Fig. 5). Treatment of apo VLDL with 2-mercaptoethanol appeared to decrease (by $<0.01 \mathrm{pH}$ unit) the apparent pI of the more cationic component.

To evaluate further the presence of these components of apo E, isoelectric focusing was performed over

TABLE III

Composition of Lipoproteins of Proband, Ad.A. (\% mass)

\begin{tabular}{lccrr}
\hline & VLDL & IDL & LDL & HDL \\
\hline Cholesteryl esters & 29.5 & 20.2 & 40.7 & 19.8 \\
Triglycerides & 27.4 & 20.9 & 7.4 & 0.2 \\
Cholesterol & 11.0 & 10.4 & 11.5 & 3.2 \\
Phospholipids & 20.5 & 24.0 & 17.8 & 21.9 \\
Protein & 11.5 & 24.5 & 22.7 & 55.0 \\
\hline
\end{tabular}

Total cholesterol and triglycerides in serum were 217 and $143 \mathrm{mg} /$ dl. Total cholesterol in VLDL, IDL, LDL, and HDL were 42, 11, 133 , and $22 \mathrm{mg} / \mathrm{dl}$, respectively. a narrower range of $\mathrm{pH}$, from 5.0 to 7.0 (Fig. 6). Under these conditions, each of the isoform regions (E-3, E2 , and E-1) was resolved into three components in all affected members of the kindred; of these, two remained after treatment of apo VLDL with 2-mercaptoethanol. No clear splitting of bands was observed in the unaffected individuals whose apo $E$ included E-3 (Fig. 7). However, apo E-2 in apo VLDL from patients with classical dysbetalipoproteinemia was seen as a doublet, with or without reduction of disulfide dimers

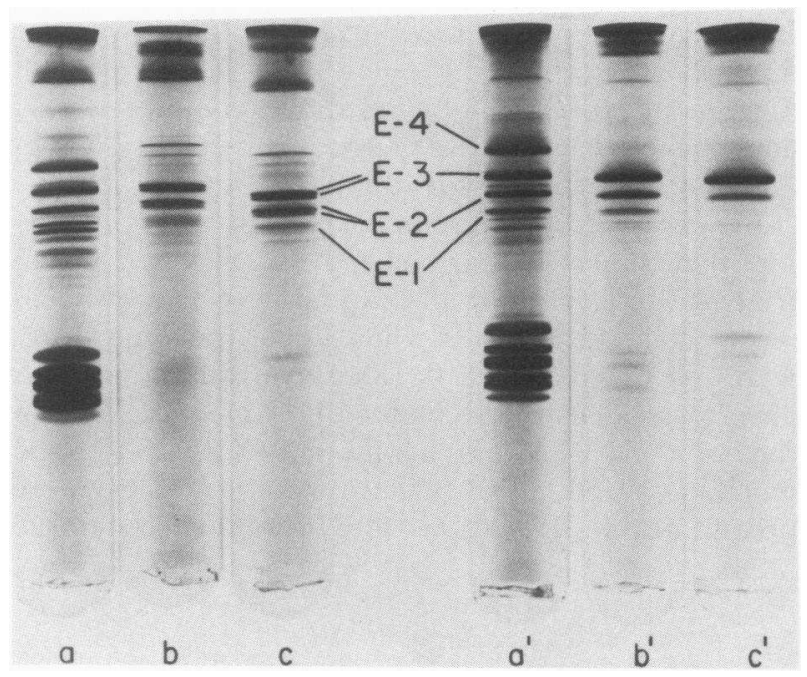

FIgURE 2 Isoelectric focusing polyacrylamide gel electrophoretograms ( $\mathrm{pH}$ gradient 3.5-7.0) of apo VLDL. For the group of three gels on the right, apo VLDL was incubated with 2-mercaptoethanol to dissociate disulfide-bonded multimers. $a, a^{\prime}$; apo VLDL from a patient with phenotype E4/ 3. $b, b^{\prime}$; apo VLDL from the proband, Ad.A. $c, c^{\prime}$; apo VLDL from the proband treated with neuraminidase. When 2-mercaptoethanol was not used, E-3 and E-2 appear as two closely spaced components of approximately equal intensity (doublets). Note also reduction of component in the region of $\mathbf{E}$ 1 in $c^{\prime}$, as compared with $b^{\prime}$. 


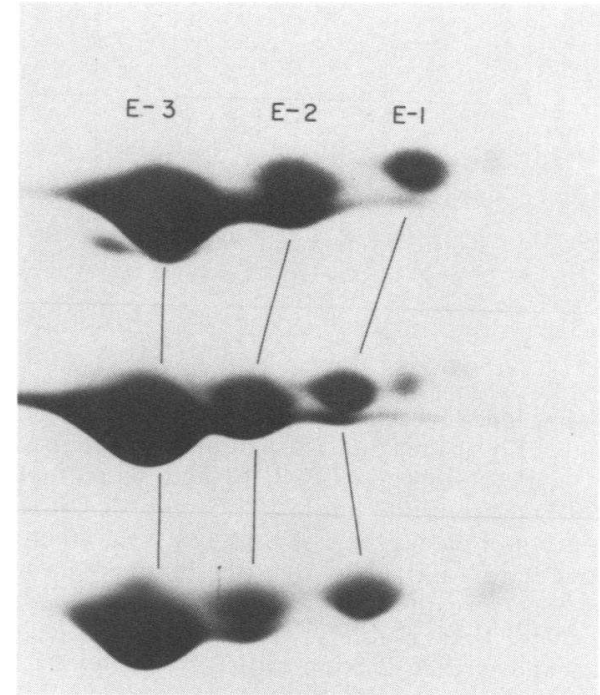

Figure 3 Two-dimensional gel electrophoretograms of apo E from VLDL of the proband Ad.A. (top), her affected child, Jo.A. (middle), and a subject with a normal E3/3 phenotype (bottom). Only the region of the gel containing components of apo $\mathrm{E}$ is shown. The distribution of both E-3 and sialylated components with the mobility of E-2 and E-1 is similar in all gels.

with 2-mercaptoethanol (Fig. 7). The doublets observed in affected members of the $A$. kindred and in persons with classical dysbetalipoproteinemia remained after treatment of apo VLDL with neuraminidase (Fig. 7). In the members of the A. kindred, the intensity of the two components of the doublet was approximately equal, whereas in those with classical dysbetalipoproteinemia the cationic member of the doublet predominated.

Composition of apo $E$ and apo B. The amino acid composition of apo $E$ from the proband and one of her affected children was indistinguishable from that of apo $E$ from unaffected persons (data not shown). Treatment of apo VLDL of the proband and her mother with cysteamine (Fig. 8) increased the $\mathrm{pI}$ of each component of apo $\mathrm{E}$ by a single charge unit, consistent with the presence of a single residue of cysteine, as with normal persons with the E3/3 phenotype $(1,21)$. As in patients with classical dysbetalipoproteinemia, the apo $B$ of the VLDL fraction of the proband and her mother contained a distinct component with the mobility of B-48 as well as B-100, consistent with the presence of partially catabolized chylomicrons as well as VLDL (Fig. 9). The apo B of VLDL of normal individuals, subjected to the same analysis, rarely contains a detectable B-48 component.

Uptake of apo $E$ by isolated rat liver. Apo $\mathrm{E}$ from the proband and one of her children was iodinated with ${ }^{125}$ I and complexed with egg lecithin. The com-

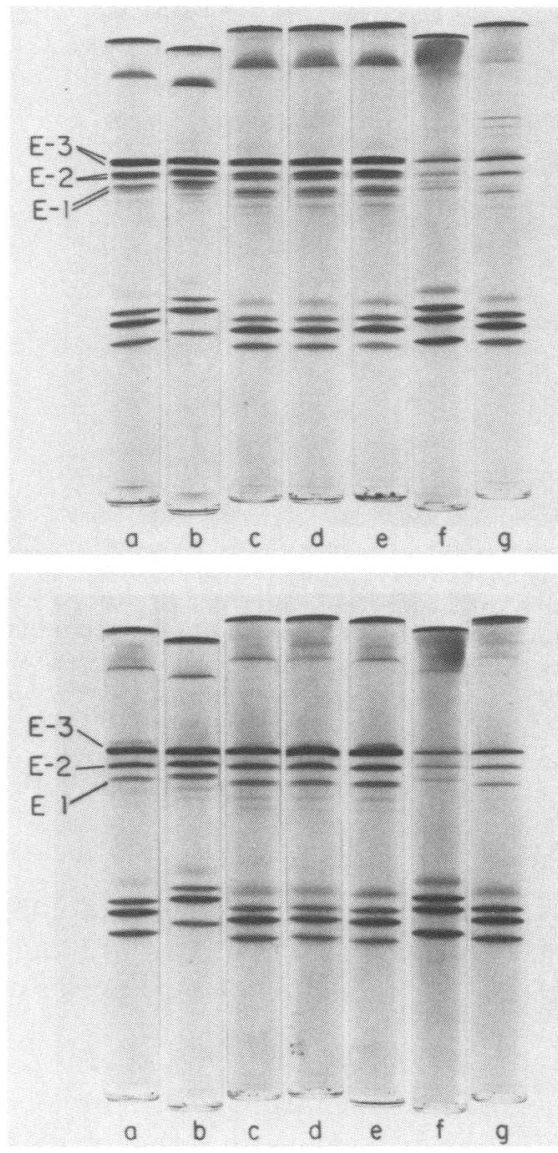

Figure 4 Isoelectric focusing gel electrophoretograms (pH gradient 3.5-7.0) of apo VLDL from five affected and two unaffected members of the A. kindred. For the lower group of gels, apo VLDL was incubated with 2-mercaptoethanol. $a, \mathrm{I}-1 ; b, \mathrm{II}-1 ; c, \mathrm{III}-3 ; d, \mathrm{III}-4 ; e$, III-2; $f$, II-2; $g$, III-5. In upper group of gels (apo VLDL not treated with 2-mercaptoethanol), $E-3$ and $E-2$ of affected members (five gels on left) appear as doublets and $E-1$ usually appears as three components. In lower group of gels, $E-3$ and $E-2$ of affected members appear as a single component and $E-1$ as two closely spaced components. Gels $c, d, e$, and $g$ were electrophoresed together; the others were run separately, accounting for slight differences in position of the components.

plexes were mainly discoidal particles $\sim 45 \times 300 \AA$, as described previously for complexes prepared from rat apo $E$ or apo $E$ from patients with phenotype $E 4 /$ 3 or E2/2 (22). The complexes were perfused through isolated livers from normal rats and rats that had been treated with large amounts of 17- $\alpha$-ethinyl estradiol for $5 \mathrm{~d}(22)$. In each case, the uptake of ${ }^{125} \mathrm{I}$-apo $\mathrm{E}$ was stimulated by $20-30 \%$ in livers of estradiol-treated, as compared with normal rats (Fig. 10). The behavior of the apo $\mathbf{E}$ from dyslipoproteinemic members of the $\mathrm{A}$. kindred therefore resembles that of apo $\mathrm{E}$ from persons with phenotype E4/3 or E3/3 (unpublished data), and 


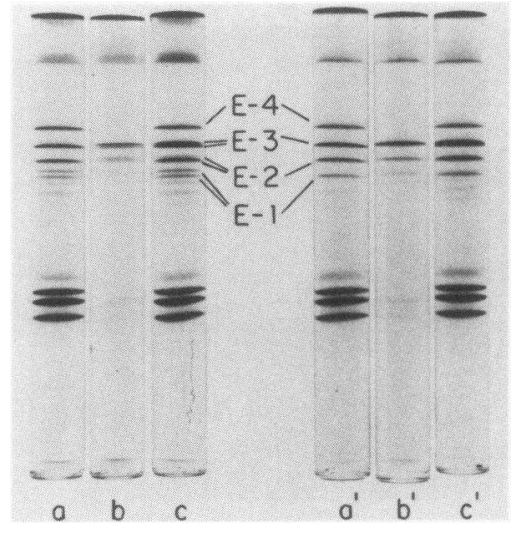

FIGURE 5 Isoelectric focusing polyacrylamide gel electrophoretograms (pH gradient 3.5-7.0) of apo VLDL. For group of three gels on right, apo VLDL was incubated with 2-mercaptoethanol. $a, a^{\prime}$; apo VLDL from a patient with phenotype E4/3. $b, b^{\prime}$; apo VLDL from proband, Ad.A. $c, c^{\prime}$; mixture of apo VLDL shown in $a, a^{\prime}$ and $b, b^{\prime}$. The lower of the two components of E-3 and E-2 from Ad.A. co-focuses with the E-3 and E-2 from the patient with phenotype E4/3.

E2/2 with cysteine at positions 112 and 145, rather than E2/2 with cysteine at positions 112 and 158 , in which little or no stimulation of uptake was observed $(6,8,22)$.

Postheparin lipolytic activities. Blood plasma was obtained from the proband and a normolipidemic subject $10 \mathrm{~min}$ after intravenous injection of $1.0 \mathrm{mg}$ heparin $/ \mathrm{kg}$ body weight. Total lipolytic activity against emulsified triglycerides (control 12.8 , proband 17.3 $\mu \mathrm{mol}$ fatty acid produced $/ \mathrm{ml}$ plasma in $1 \mathrm{~h}$ ) and activity resistant to $1.0 \mathrm{M} \mathrm{NaCl}$ (control 6.6 , proband 4.9 $\mu \mathrm{mol}$ fatty acid produced $/ \mathrm{ml}$ plasma in $1 \mathrm{~h}$ ) were similar.

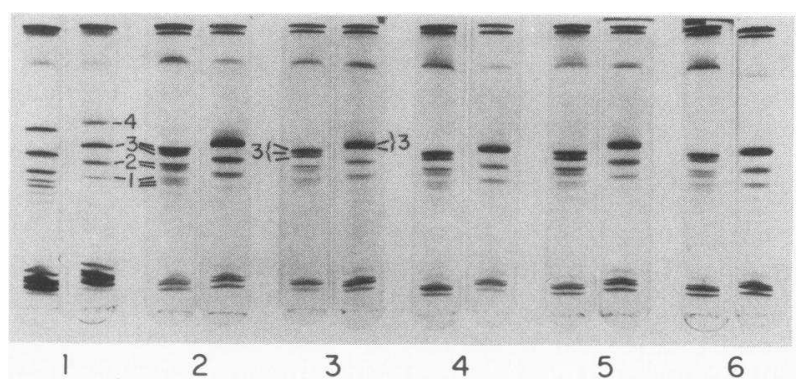

FIGURE 6 Isoelectric focusing polyacrylamide gel electrophoretograms of apo VLDL (pH gradient 5.0-7.0): (1) patient with phenotype E4/3; (2-6) five affected members of A. kindred. In apo VLDL not treated with 2-mercaptoethanol (left member of each pair), E-3, E-2, and E-1 appear as three closely spaced components; in apo VLDL treated with 2-mercaptoethanol (right member of each pair), only two closely spaced components are evident.

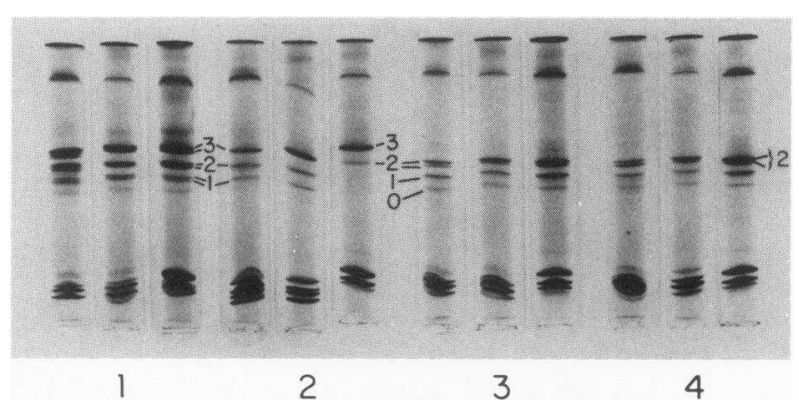

Figure 7 Isoelectric focusing gel electrophoretograms of apo VLDL (pH gradient 5.0-7.0) from: (1) proband Ad.A.; (2) patient with phenotype E3/3; (3 and 4) patients with classical dysbetalipoproteinemia. The apo VLDL for the middle member of each group of three gels was treated with 2-mercaptoethanol and that for the right member was treated with 2-mercaptoethanol and incubated with neuraminidase. Note that doublets seen with E-3, E-2 and E-1 from Ad.A. and with E-2 from patients with classical dysbetalipoproteinemia are unaffected by treatment of apo VLDL with neuraminidase. In Ad.A., the doublets stain with approximately equal intensity, whereas in those of E-2 from patients with classical dysbetalipoproteinemia, the more cationic component predominates. All isoforms from the patient with the usual E3/3 phenotype appear as single bands.

\section{DISCUSSION}

VLDL of many persons contain two electrophoretic components, the more slowly migrating of which has properties resembling those of VLDL remnants (17). In a few persons without other evidences of dysbetali-

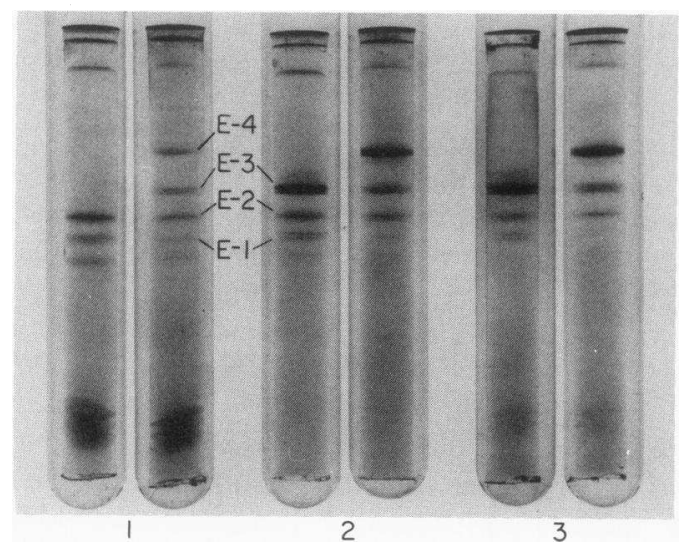

Figure 8 Effect of treatment of apo VLDL with cysteamine upon the isoelectric focusing patterns of apo $E$. The apo VLDL of the left member of each pair of gels was reduced with $\beta$-mercaptoethanol; the apo VLDL of the right member was treated with cysteamine to convert cysteine residues to a positively charged derivative. Left pair of gels, patient with classical dysbetalipoproteinemia; middle pair of gels, proband Ad.A.; right pair of gels, proband's mother G.P. The predominant E-3 component of Ad.A. and G.P. is shifted to the position of E-4. The pI of E-2 and E-1 is also increased by a single charge unit. 


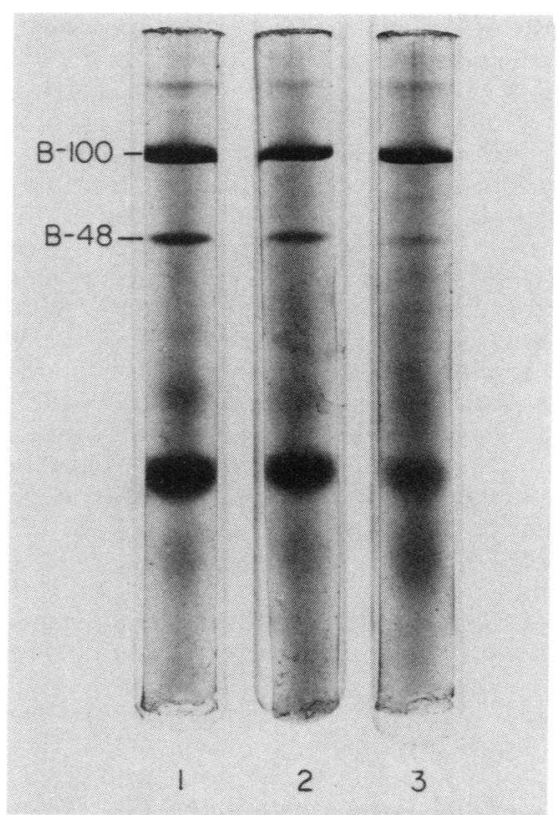

FIGURE 9 SDS polyacrylamide gel (3\%) electrophoretograms of apoproteins of VLDL from (1) proband Ad.A., (2) proband's mother, G.P., and (3) a patient with classical dysbetalipoproteinemia. In each case, the major high molecular weight component has the mobility of apo B-100 and a minor component has the mobility of apo B-48.

poproteinemia, the mobility of the more slowly migrating component overlaps that of LDL, and is therefore designated as $\beta$-VLDL. However, only persons with apo $E$ phenotype $E 2 / 2$ or absence of apo $E$ have heretofore been found to have $\beta$-VLDL with very high content of cholesteryl esters, associated with tuberous or palmar xanthomas $(1,7)$. The affected members of the A. kindred present all of the characteristic clinical and biochemical features of familial dysbetalipoproteinemia except phenotype E2/2. They, as well as the unaffected father of the three affected children of the proband, have phenotype E3/3. If the father's E-3 is normal (i.e., if it contains a single cysteine at position 112), these children must be presumed to have one allele for apo $E$ that specifies a normal protein; yet their lipoprotein abnormality is as severe as that of their mother and grandmother. Their lipoproteins are typical of persons with phenotype E2/2, which is presumed to reflect homozygosity for a form of apo $\mathrm{E}$ that, at least as present in plasma lipoproteins, reacts poorly with cell surface receptors (1). If the apo $E$ specified by a normal apo E-3 allele is expressed in these children, it must be presumed that it is ineffective in promoting the metabolism of remnants of triglyceride-rich lipoproteins. On the other hand, the father may be heterozygous for two alleles, each of which specifies E-3, and one of which reacts poorly

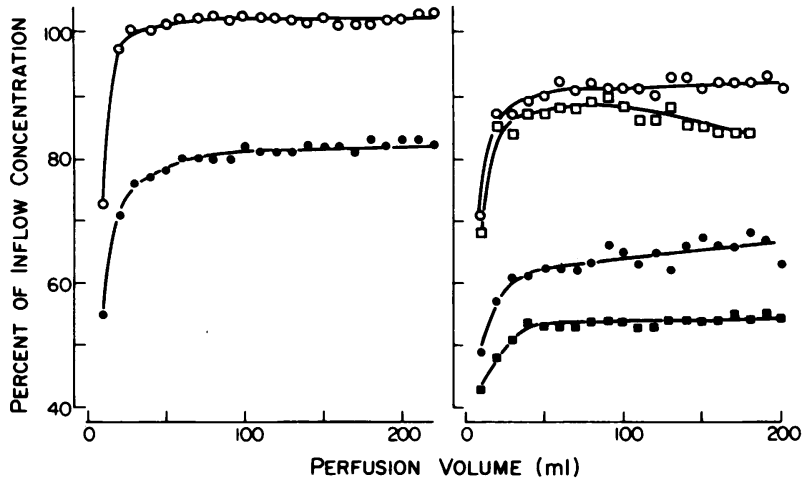

Figure 10 Uptake of ${ }^{125} \mathrm{I}$-apo $\mathrm{E}$ in lamellar complexes into livers of control $(O)$ and estradiol-treated $(\Theta)$ rats perfused in a single-pass system at a rate of $12 \mathrm{ml} / \mathrm{min}$. Medium containing no complexes was replaced by medium containing labeled complexes at the beginning of the collection periods shown, and all perfusate was collected in $10-\mathrm{ml}$ portions during the next $17 \mathrm{~min}$. Panel on left shows a paired experiment with apo $E$ from proband, Ad.A. (concentration of apo $\mathrm{E}$ in perfusate was $0.34 \mu \mathrm{g} / \mathrm{ml}$ ); panel on right shows two paired experiments with apo $E$ from proband's daughter, M.A.A. (concentration of apo $E$ in perfusate was 0.31 $\mu \mathrm{g} / \mathrm{ml})$.

with cell surface receptors. The three affected children, then, could have two alleles specifying synthesis of apo E-3, each of which is functionally defective. The observation that the E-3 and E-2 are each composed of two components, approximately equal in amount and differing in $\mathrm{pI}$ by $\sim 0.01 \mathrm{pH}$ unit, after reduction of disulfide dimers with 2 -mercaptoethanol (Fig. 6) and desialylation of the protein by treatment of neuraminidase (Fig. 7), is consistent with heterozygosity for such alleles in all five affected members of the family. The presence of doublets in the apo E2 of patients with classical dysbetalipoproteinemia (Fig. 7), makes the significance of this observation somewhat uncertain, but one component of those doublets was less prominent than the other.

An alternate explanation for the occurrence of dysbetalipoproteinemia in this kindred is that they lack the normal receptor-dependent mechanisms for processing remnants of triglyceride-rich lipoproteins in the liver. Apo E reacts with several lipoprotein receptors, including receptors on cells in extrahepatic tissues and receptors in the liver. Under some conditions, the liver expresses the LDL receptor first described in cultured human fibroblasts (25). This receptor recognizes lipoproteins or lipid-protein complexes containing apo B-100, the B apoprotein secreted by the liver (26), and apo $E$, which is also secreted from the liver (27). In addition, liver membranes have a binding site for lipoproteins containing apo E but not apo B-100 (28). In principle, one or both of these receptors could there- 
fore participate in the uptake and catabolism of remnant lipoproteins. We found that the apo $\mathrm{E}$ of affected members was effectively recognized by the estradiolinduced LDL receptor of rat liver (Fig. 10). Although this observation is consistent with a defect in an hepatic receptor or receptors, it is now known that the apo E2 from patients with classical dysbetalipoproteinemia can differ both structurally and functionally. Thus, the apo E-2 from a patient in which cysteine is present at positions 112 and $145(6)$ is also taken up readily in livers of estradiol-treated rats (8) and reacts almost normally with LDL receptors in cells and cell membrane preparations $(6,8)$. It seems unlikely that this patient has both a defective apo $E$ and defective hepatic remnant receptors. In addition, recent studies in Watanabe heritable hyperlipidemic rabbits, which lack hepatic LDL receptors, suggest that partially catabolized chylomicrons and VLDL may be processed differently by hepatic receptors. The metabolism of chylomicrons is normal in Watanabe heritable hyperlipidemic rabbits (29), but that of VLDL is impaired (30), consistent with the hypothesis that chylomicron remnants are processed by apo $\mathrm{E}$ receptors, whereas partially catabolized VLDL are processed at least in part by the LDL receptor that recognizes both apo B100 and apo E. As in patients with classical dysbetalipoproteinemia $(1,31,32)$, both chylomicron remnants and VLDL remnants appear to accumulate in the affected members of the A. kindred. It therefore seems more likely that they will be found to have one or two structurally abnormal apo $\mathrm{E}$ that contain a single cysteine residue.

The observations presented here are consistent with other evidence that multiple mutations of apo $E$ cause dysbetalipoproteinemia. The present observations suggest that such mutations may be associated with the E3/3 phenotype.

\section{ACKNOWLEDGMENTS}

We thank Dr. Morris Schambelan for referring this family for study, Dr. Karl Weisgraber for performing the two-dimensional gel analysis, and Dr. Philip H. Frost for performing the assays of postheparin lipolytic activities.

This work was carried out in part at the General Clinical Research Center, San Francisco General Hospital with support (RR00083) by the Division of Research Resources, National Institutes of Health, and by a grant from the National Heart, Lung, and Blood Institute (HL 14237, Arteriosclerosis Specialized Center of Research).

\section{REFERENCES}

1. Havel, R. J. 1982. Familial dysbetalipoproteinemia: new aspects of pathogenesis and diagnosis. Med. Clin. N. Am. 66:441-454.

2. Zannis, V. I., J. L. Breslow, G. Utermann, R. W. Mahley, K. H. Weisgraber, R. J. Havel, J. L. Goldstein, M. S. Brown, G. Schonfeld, W. R. Hazzard, and C. Blum. 1982.
Proposed nomenclature of apo $E$ isoproteins, apo $E$ genotypes, and phenotypes. J. Lipid Res. 23:911-914.

3. Zannis, V. I., and J. L. Breslow. 1981. Human very low density lipoprotein apolipoprotein $\mathrm{E}$ isoprotein polymorphism is explained by genetic variation and posttranslational modification. Biochemistry. 20:1033-1041.

4. Weisgraber, K. H., S. C. Rall, Jr., and R. W. Mahley. 1981. Human $\mathrm{E}$ apoprotein heterogeneity: cysteine-arginine interchanges in the amino acid sequence of the apo-E isoforms. J. Biol. Chem. 256:9077-9083.

5. Rall, S. C., Jr., K. H. Weisgraber, and R. W. Mahley. 1982. Human apolipoprotein $\mathrm{E}$. The complete amino acid sequence. J. Biol. Chem. 257:4171-4178.

6. Rall, S. C., Jr., K. H. Weisgraber, T. L. Innerarity, and R. W. Mahley. 1982. Structural basis for receptor binding heterogeneity of apolipoprotein $E$ from type III hyperlipoproteinemic subjects. Proc. Natl. Acad. Sci. USA. 79:4696-4700.

7. Ghiselli, G., E. J. Schaefer, P. Gascon, and H. B. Brewer, Jr. 1981. Type II hyperlipoproteinemia associated with apolipoprotein E deficiency. Science (Wash. DC). 214:1239-1241.

8. Schneider, W. J., P. T. Kovanen, M. S. Brown, J. L. Goldstein, G. Utermann, W. Weber, R. J. Havel, L. Kotite, J. P. Kane, T. L. Innerarity, and R. W. Mahley. 1981. Familial dysbetalipoproteinemia. Abnormal binding of mutant apoprotein $\mathrm{E}$ to low density lipoprotein receptors of human fibroblasts and membranes from liver and adrenal of rats, rabbits, and cows. J. Clin. Invest. 68:1075-1085.

9. Rush, R. L., L. Leon, and J. Turrell. 1970. Automated simultaneous cholesterol and triglyceride determinations on the Autoanalyzer II instrument. In Advances in automated analysis. Technicon International Congress1970/Clinical Analysis. Futura Publishing Co., Inc., Mt. Kisco, NY. 1:503-507.

10. Havel, R. J., L. Kotite, J.-L. Vigne, J. P. Kane, P. Tun, N. Phillips, and G. C. Chen. 1980. Radioimmunoassay of human arginine-rich apolipoprotein, apoprotein $\mathbf{E}$. Concentration in blood plasma and lipoproteins as affected by apoprotein E-3 deficiency. J. Clin. Invest. 66:1351-1362.

11. Myers, L. H., N. R. Phillips, and R. J. Havel. 1976. Mathematical evaluation of methods for estimation of the concentration of the major lipid components of human serum lipoproteins. J. Lab. Clin. Med. 88:491-505.

12. Havel, R. J., T. Kita, L. Kotite, J. P. Kane, R. J. Hamilton, J. L. Goldstein, and M. S. Brown. 1982. Concentration and composition of lipoproteins in blood plasma of the WHHL rabbit, an animal model of human familial hypercholesterolemia. Arteriosclerosis. 2:467-474.

13. Havel, R. J., H. Eder, and J. Bragdon. 1955. The distribution and chemical composition of ultracentrifugation separated lipoproteins in human serum. J. Clin. Invest. 34:1345-1353.

14. Kane, J. P., T. Sata, R. L. Hamilton, and R. J. Havel. 1975. Apoprotein composition of very low density lipoproteins in human serum. J. Clin. Invest. 56:16221634.

15. Scanu, A. M., and C. Edelstein. 1971. Solubility in aqueous solutions of ethanol of the small molecular weight peptides of the serum very low density and high density lipoproteins: relevance to the recovery problem during delipidation of serum lipoproteins. Anal. Biochem. 44:576-588.

16. Kane, J. P., D. A. Hardman, and H. E. Paulus. 1980. Heterogeneity of apolipoprotein B: isolation of a new 
species from human chylomicrons. Proc. Natl. Acad. Sci. USA. 77:2465-2469.

17. Pagnan, A., R. J. Havel, J. P. Kane, and L. Kotite. 1977. Characterization of human very low density lipoproteins containing two electrophoretic populations: double prebeta lipoproteinemia and primary dysbetalipoproteinemia. J. Lipid Res. 18:613-622.

18. Menzel, H.-J., R.-G. Kladetzky, and G. Assmann. 1982. One step screening method for the polymorphism of apolipoproteins A-I, A-II, and A-IV. J. Lipid Res. 23:915-922.

19. Fainaru, M., R. J. Havel, and K. Imaizumi. 1977. Radioimmunoassay of arginine-rich apolipoprotein of rat serum. Biochim. Biophys. Acta. 490:144-155.

20. Spackman, K. H. 1967. Accelerated methods. Methods Enzymol. 11:3-15.

21. Weisgraber, K. H., T. L. Innerarity, and R. W. Mahley. 1982. Abnormal lipoprotein receptor-binding activity of the human $\mathrm{E}$ apoprotein due to cysteine-arginine interchange at a single site. J. Biol. Chem. 257:2518-2521.

22. Havel, R. J., Y.s. Chao, E. E. Windler, L. Kotite, and L. S. S. Guo. 1980. Isoprotein specificity in the hepatic uptake of apolipoprotein $\mathrm{E}$ and the pathogenesis of $\mathrm{fa}$ milial dysbetalipoproteinemia. Proc. Natl. Acad. Sci. USA. 77:4349-4353.

23. Frost, P. H., V. G. Shore, and R. J. Havel. 1982. Purification of canine post-heparin hepatic lipase. Biochim. Biophys. Acta. 712:71-78.

24. Havel, R. J., J. L. Goldstein, and M. S. Brown. 1980. Lipoproteins and lipid transport. In Metabolic Control and Disease. P. K. Bondy and L. E. Rosenberg, editors. W. B. Saunders Co., Philadelphia. Eighth ed. 393-494.
25. Brown, M. S., P. T. Kovanen, and J. L. Goldstein. 1981. Regulation of plasma cholesterol by lipoprotein receptors. Science (Wash. DC). 212:628-635.

26. Malloy, M. J., J. P. Kane, D. A. Hardman, R. L. Hamilton, and K. B. Dalal. 1981. Normotriglyceridemic abetalipoproteinemia. Absence of the B-100 apolipoprotein. J. Clin. Invest. 67:1441-1450.

27. Havel, R. J. 1980. Lipoprotein biosynthesis and metabolism. Ann. NY Acad. Sci. 348:16-27.

28. Mahley, R. W., D. Y. Hui, T. L. Innerarity, and K. H. Weisgraber. 1981. Two independent lipoprotein receptors on hepatic membranes of dog, swine, and man. ApoB,E and apo-E receptors. J. Clin. Invest. 68:1197-1206.

29. Kita, T., J. L. Goldstein, M. S. Brown. Y. Watanabe, C. A. Hornick, and R. J. Havel. 1982. Hepatic uptake of chylomicron remnants in WHHL rabbits: a mechanism genetically distinct from the low density lipoprotein receptor. Proc. Natl. Acad. Sci. USA. 79:3623-3627.

30. Kita, T., M. S. Brown, D. W. Bilheimer, and J. L. Goldstein. 1982. Delayed clearance of very low density and intermediate density lipoproteins with enhanced conversion to low density lipoprotein in WHHL rabbits. Proc. Natl. Acad. Sci. USA. 79:5693-5697.

31. Fainaru, M., R. W. Mahley, R. L. Hamilton, and T. L. Innerarity. 1982. Structural and metabolic heterogeneity of $\beta$-very low density lipoproteins from cholesterol-fed dogs and from humans with Type III hyperlipoproteinemia. J. Lipid Res. 23:702-714.

32. Kane, J. P., G. C. Chen, R. L. Hamilton, D. A. Hardman, M. J. Malloy, and R. J. Havel. 1983. Remnants of lipoproteins of intestinal and hepatic origin in familial dysbetalipoproteinemia. Arteriosclerosis. 3:47-56. 